\title{
Olefin Polymerization by Late Transition Metal Complexes- A Root of Ziegler Catalysts Gains New Ground
}

\author{
Stefan Mecking*
}

\section{Introduction}

Polyolefins are of vast economic importance, which is reflected by an annual production of more than 70 million tons of polyethylene and polypropylene. While the major portion of these materials is produced with Ziegler- and chromium-based catalysts, the older free-radical process that affords low-density polyethylene (LDPE) has maintained its significance. ${ }^{[1]}$ Despite the necessity of working at over 1500 bar, 16 million tons of LDPE are currently consumed annually and new large plants continue to be built. ${ }^{[1 \mathrm{~d}, \mathrm{e}]}$ One attractive feature of the high-pressure process is the possibility of incorporating functionalized olefins, such as vinyl acetate or acrylates. Incorporation of even small amounts of polar moieties can increase adhesion properties and compatibility of polyolefins with other materials. Another attractive feature is the different property profile of LDPE compared to the linear ethylene homo- and copolymers produced by Ziegler catalysts. In the free-radical polymerization of ethylene, short- as well as long-chain branches are formed without any added co-monomer. Short-chain branches affect polymer properties, such as crystallinity and melting temperature, and are important in controlling polyolefin application properties. Long-chain branches (typically containing 100 or more carbon atoms) particularly influence the rheology of polyolefin melts, and result in good processing properties of LDPE.

These considerations exemplify existing challenges for transition metal catalyzed coordination polymerization in low-pressure processes. In regard to the desirable incorporation of polar monomers, early transition metal based Ziegler catalysts and metallocenes are, unfortunately, highly sensitive to polar reagents. By comparison, late transition

[*] Dr. S. Mecking

Institut für Makromolekulare Chemie und Freiburger Materialforschungszentrum der Albert-Ludwigs-Universität Freiburg

Stefan-Meier-Strasse 31, 79104 Freiburg (Germany)

Fax: (+49) 761-203-6319

E-mail: mecking@uni-freiburg.de metal complexes are generally much more functional-group tolerant as a result of their less oxophilic nature. In addition, they can provide access to unique polyolefin branching structures. Recent discoveries of novel olefin-polymerization catalysts based on late transition metals represent major advances. These findings are highlighted and put into perspective with previous developments, by using ethylene polymerization as a guideline. ${ }^{[2,3]}$

\section{General Aspects of Catalyst Design}

Polymerization of ethylene or $\alpha$-olefins by Ziegler-Natta or metallocene catalysis and $\mathrm{C}-\mathrm{C}$ linkage by late transition metal complexes rely on the same basic types of reactions, namely chain growth by migratory insertion in alkyl-olefin complexes and chain transfer by various mechanisms. However, late transition metal catalysts usually yield dimers or oligomers because of the propensity of alkyl complexes of late transition metals for chain transfer by $\beta$-hydride elimination (Scheme 1)..$^{[4,5 c]}$ A prominent example is the Shell Higher Olefin Process (SHOP), developed by Keim et al. in the 1960s and 1970 s, in which linear $\alpha$-olefins are obtained by nickel-

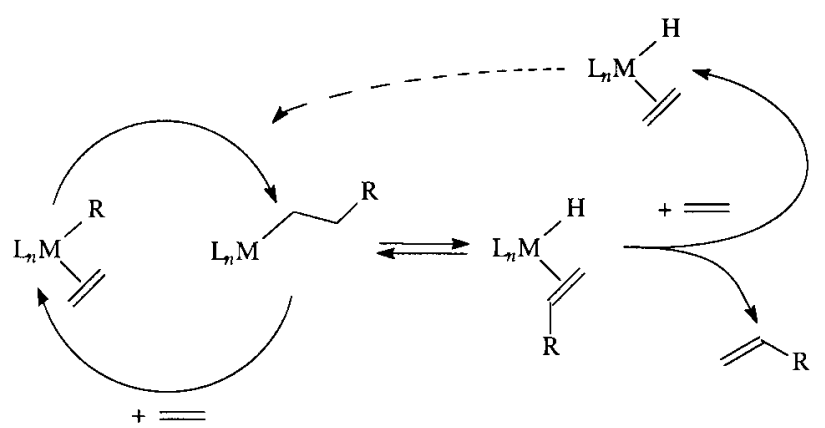

chain growth

chain transfer by $\beta$-hydride elimination

Scheme 1. Simplified schematic representation of ethylene oligomerization and polymerization by late transition metal $(\mathrm{M})$ complexes $(\mathrm{R}=$ growing polymer/oligomer chain). 
catalyzed oligomerization of ethylene [Eq. (1)].. ${ }^{[4]}$ A late transition metal catalyzed ethylene oligomerization reaction

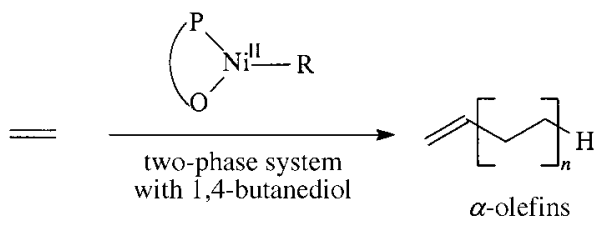

\section{$\Longrightarrow$ detergents}

can also be regarded as a direct forerunner of today's polyolefin industry. After all, it was the observation that a combination of trace impurities of nickel compounds with aluminumalkyl compounds catalyzed ethylene dimerization (the famous "nickel effect") that led directly to the discovery of Ziegler catalysts. ${ }^{[5]}$

A prime objective of research on olefin polymerization by late transition metal complexes is the design of catalysts capable of producing high molecular weight products. In mechanistic terms this translates to a supression of chain transfer, while at the same time maintaining a high chaingrowth rate (Scheme 1). For a given chain-growth rate, an increase in the barrier to chain transfer of $\Delta \Delta \mathrm{G}^{\mp} \approx 3-4 \mathrm{kcal}$ will turn an oligomerization into a polymerization catalyst.

Most known effective polymerization systems are based either on neutral nickel(II) complexes of formally monoanionic bidentate ligands (Scheme 2; 1) or on cationic iron,<smiles>[R][N+]1([3H])CCO1</smiles>

1

XO: formally monoanionic bidentate ligand $(\mathrm{X}=\mathrm{P}$ or $\mathrm{N})$

Scheme 2. Structure of some ethylene polymerization catalysts based on neutral or cationic late transition metal complexes. In well-defined catalyst precursors $\mathrm{R}$ is either a $\mathrm{Ph}$ or Me ligand which is capable of initiating chain growth. L is a monodentate ligand which is generally weakly coordinating and capable of being displaced by the monomer. In the presumed active species, $\mathrm{R}$ is usually the growing polymer chain and $\mathrm{L}$ is usually the monomer or solvent.

cobalt, nickel, or palladium complexes of neutral multidentate ligands with nitrogen donor atoms substituted with bulky groups (2). ${ }^{[6,7,15,16,21,25,27,28]}$ The molecular weight of the polymer produced is controlled by both electronic and steric properties imparted by the bi- or tridentate ligands alike (see below). The chelating ligands in $\mathbf{1}$ and $\mathbf{2}$ will keep the growing polymer chain and coordinated monomer relatively close (for example, in a cis position in square-planar complexes).${ }^{[7]}$ Also, most catalyst systems are characterized by the absence of additional strongly coordinating ligands (L), which can block coordination sites during catalysis and favor the formation of low molecular weight products. ${ }^{[4 b]}$ Thus, the typical SHOPtype oligomerization catalyst $\mathbf{3}^{[4 \mathrm{~b}, \mathrm{c}]}$ produces linear polyethylene upon scavenging of the triphenylphosphane ligand (Scheme 3). ${ }^{[16]}$

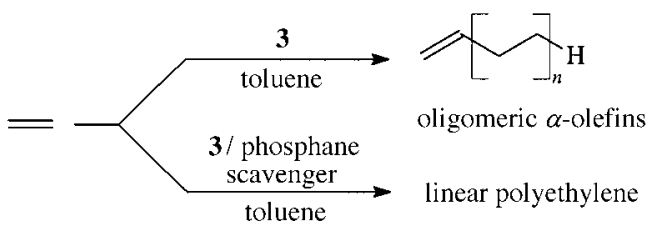<smiles>C1=C(c2ccccc2)P(c2ccccc2)(c2ccccc2)(c2ccccc2)c2ccccc21</smiles>

3

Scheme 3. Effect of a monodentate triphenylphosphane ligand on the molecular weight of the product.

In the context of preparating functionalized olefin polymers by late transition metal catalysis, it is interesting to note that for the particular case of alternating copolymerization of olefins and CO by cationic palladium complexes (Scheme 4),

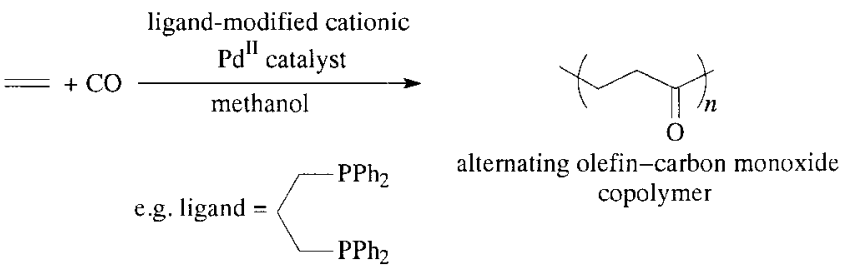

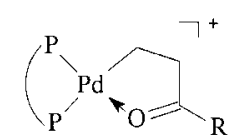

proposed chelation after an ethylene insertion<smiles>[R]C(=O)CCC(=O)[R]1(C=O)NCCN1</smiles>

catalyst resting state (for $\widehat{\mathrm{NN}}=1,10$-phenanthroline)
Scheme 4. Copolymerization of olefins with carbon monoxide and the effect of $\mathrm{CO}$ monomer on chain transfer.

a much larger variety of bidentate ligands can be used. ${ }^{[8]}$ It has been suggested that steric constraints imposed by chelating coordination of a $\beta$-carbonyl group after an ethylene insertion are responsible for preventing $\beta$-hydride elimination. ${ }^{[8 a]}$ Furthermore, ethylene insertion is followed by a rapid CO insertion, such that an acyl complex (not susceptible to $\beta$ hydride elimination) is the catalyst resting state. ${ }^{\left[{ }^{9 c]}\right]}$ Accordingly, the bisphosphane-based catalysts typically used for ethylene/CO copolymerization dimerize ethylene in the absence of $\mathrm{CO} .^{[9]}$ The strictly alternating polyketones obtained by ethylene/ $\mathrm{CO} /$ propylene terpolymerization have good chemical resistance and mechanical wear properties. However, the presence of a large number of carbonyl groups renders these polymers sensitive to UV light; furthermore, undesired condensation cross-linking during processing can occur. Such semicrystalline engineering thermoplastics have been produced commercially by Shell since 1995 but it was recently announced that this business is to be abandoned. ${ }^{[10]}$ The vinyl-type polymerization of functionalized norbornenes can also be performed using a variety of palladium(II) and also nickel(II) catalysts. ${ }^{[1]}$ Again, steric constraints most likely contribute to retardation of chain transfer. 
Previous History-Polymerization by Neutral Nickel(II) Catalysts with a Chelating Ligand

In the SHOP, ethylene oligomerization is catalyzed by neutral nickel(II) complexes with chelating PO ligands [Eq. (1)]. The functional-group tolerance of the nickel(II) catalyst allows for the use of 1,4-butanediol as a polar catalyst phase. Hereby, the process can be run in a two-phase mode, and allows for the simple seperation of the apolar products from the catalyst. ${ }^{[4 \mathrm{~d}]}$ In the development of the SHOP, and in subsequent related academic research, a number of ethylene polymerization catalysts were discovered. ${ }^{[4 c, 12,13 \mathrm{~b}]}$ Mostly, they convert ethylene into linear polyethylene with moderate activities (some $1000 \mathrm{TOh}^{-1} ; M_{\mathrm{v}}$ up to $10^{5} \mathrm{~g} \mathrm{~mol}^{-1}$; $\mathrm{TO}=$ turnover $=$ mol substrate converted per mol metal). By contrast, the catalyst system $\left[\mathrm{Ni}(\operatorname{cod})_{2}\right] /\left(\mathrm{Me}_{3} \mathrm{Si}\right)_{2} \mathrm{~N}-\mathrm{P}-$ $\left(=\mathrm{NSiMe}_{3}\right)_{2}(\operatorname{cod}=1,5$-cyclooctadiene $)$ was found to convert ethylene into a branched polymer. ${ }^{[13]}$ The moderate molecular weight polyethylene $\left(M_{\mathrm{n}} \approx 7 \times 10^{3} \mathrm{~g} \mathrm{~mol}^{-1}\right)$ posesses methyl and longer chain branches. This surprising microstructure was proposed to result from simultaneous linear oligomerization of ethylene and subsequent incorporation of the resulting oligomers into the polymer. ${ }^{[13 b, c]}$ A detailed investigation by Fink and co-workers of $\alpha$-olefin polymerization by such catalysts revealed polymerization occurred in a 2, $\omega$ fashion, to yield polymers containing only methyl branches. ${ }^{[14]}$ This remarkable polymer results from chain growth by 1,2 insertion, followed by a nickel migration prior to the next olefin insertion [Eq. (2)].

In the 1980 s, Ostoja-Starzewski and co-workers ${ }^{[15]}$ and Klabunde et al. ${ }^{[16]}$ extensively investigated ethylene polymerization by neutral nickel(II) complexes with P,O ligands. In comparison to $\mathbf{3}$ (Scheme 3) the replacement of the strongly binding triphenylphosphane ligand by a weakly coordinating phosphane oxide ${ }^{[15]}$ or pyridine ${ }^{[16]}$ eliminates any need for a phosphane scavenger. Complexes with electron-rich ylide ligands $\left(\mathrm{L}=\mathrm{CR}_{2}^{\prime} \mathrm{PR}_{3}\right.$ ) have also been investigated intensive-
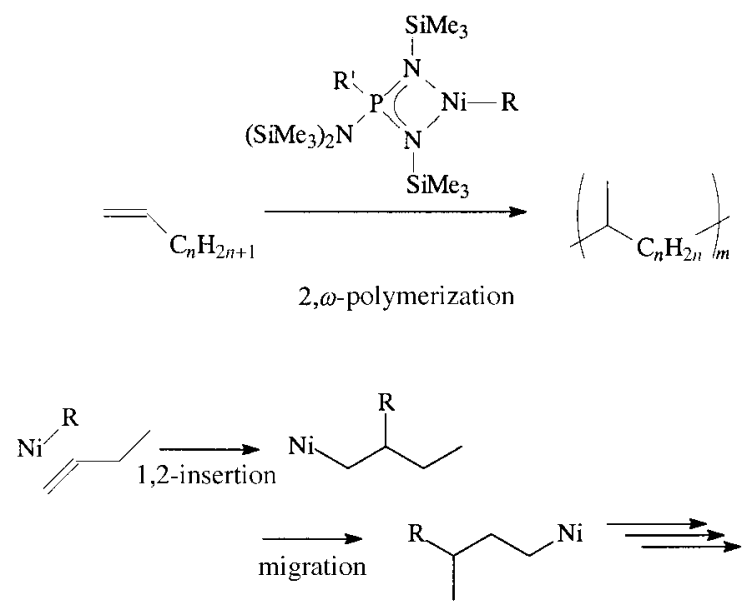

ly. ${ }^{[15,17 a]}$ These nickel(II) complexes are single-component, activator-free catalyst precursors for ethylene polymerization. By variation of the ligand structure (for example, 4 and 5),

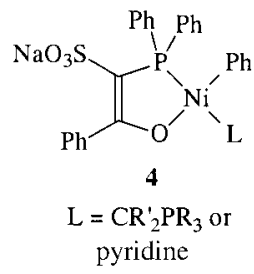

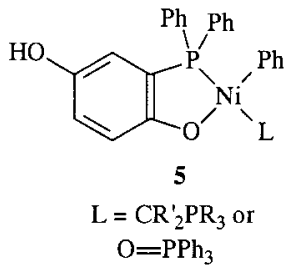

linear polyethylenes of very high molecular weight are accessible (Table 1). ${ }^{[15,17 \mathrm{~b}]}$ Productivities of $5 \times 10^{4} \mathrm{TOh}^{-1}$ were observed in typical polymerization experiments, and up to $1.8 \times 10^{5} \mathrm{TOh}^{-1}$ (at 17 bar ethylene) were reported with further optimized P,O ligands. ${ }^{[18]}$ These polymerization catalysts are also active in polar organic reaction media, such as acetone, DMF, or alcohols. ${ }^{[15 b, d, e, ~ 16 b]}$ Attempted copolymerization of ethylene with methyl acrylate or vinyl acetate was

Table 1. Examples of ethylene polymerization by late transition metal complexes. ${ }^{[\mathrm{a}]}$

\begin{tabular}{|c|c|c|c|c|c|c|}
\hline \multirow[t]{2}{*}{ Year } & \multirow[t]{2}{*}{ Catalyst type } & \multirow{2}{*}{$\begin{array}{l}\text { Typical } \\
\text { activity } \\
{\left[\mathrm{TO} \mathrm{h}^{-1}\right]}\end{array}$} & \multicolumn{2}{|c|}{$\begin{array}{c}\text { Typical polymer molecular } \\
\text { weights obtainable }\left[\mathrm{g} \mathrm{mol}^{-1}\right]^{[\mathrm{a}]}\end{array}$} & \multirow{2}{*}{$\begin{array}{l}\text { Polyethylene } \\
\text { branching } \\
\text { structure }\end{array}$} & \multirow[t]{2}{*}{ Functional group tolerance } \\
\hline & & & $M_{\mathrm{w}}$ & $M_{\mathrm{w}} / M_{\mathrm{n}}$ & & \\
\hline $1980 \mathrm{~s}$ & $\begin{array}{l}\text { neutral } \mathrm{Ni}^{\mathrm{II}} \overparen{\mathrm{PO}} \text { complexes, } \\
\text { optimized for } \\
\text { polymerization }(\mathbf{4}, \mathbf{5})\end{array}$ & $1.8 \times 10^{5}$ & $10^{6}\left(M_{v}\right)$ & $25^{[\mathrm{c}]}$ & essentially linear ${ }^{[17 b]}$ & $\begin{array}{l}\text { Stable in various polar organic } \\
\text { media; copolymerization of spe- } \\
\text { cial functionalized monomers }\end{array}$ \\
\hline 1995 & $\begin{array}{l}\text { cationic } \mathrm{Ni}^{\mathrm{II}} \text { and } \mathrm{Pd}^{\mathrm{II}} \\
\text { complexes } 6\end{array}$ & $\begin{array}{l}4 \times 10^{6}(\mathrm{Ni}) \\
4 \times 10^{3}(\mathrm{Pd})\end{array}$ & $>8 \times 10^{5}$ & 1.5 to 3 & $\begin{array}{l}\text { highly branched to lin- } \\
\text { ear; Me, Et, Pr, Bu and } \\
\text { longer. Hyperbranched } \\
\text { structures }(\mathrm{Pd})\end{array}$ & $\begin{array}{l}\text { Copolymerization of simple polar } \\
\text { monomers, such as acrylates (Pd); } \\
\text { stable in esters, acetone or water } \\
\text { (Pd) }\end{array}$ \\
\hline 1998 & cationic $\mathrm{Fe}^{\mathrm{II}}$ and $\mathrm{Co}^{\mathrm{II}}$ complexes 7 & $10^{7}(\mathrm{Fe})$ & $6 \times 10^{5}$ & 9 & highly linear & not reported to date \\
\hline 1998 & neutral $\mathrm{Ni}^{\mathrm{II}} \overparen{\mathrm{NO}}$ complexes 8 & $2.3 \times 10^{5}$ & $5 \times 10^{5}$ & 1.5 to 3 & $\begin{array}{l}\text { moderately branched to } \\
\text { linear; predominantly } \\
\mathrm{Me}, \text { also Et, } \mathrm{Pr}, \mathrm{Bu}\end{array}$ & $\begin{array}{l}\text { stable to added amounts of polar } \\
\text { organic solvents and water; co- } \\
\text { polymerization of functionalized } \\
\text { norbornenes }\end{array}$ \\
\hline
\end{tabular}

[a] Activities have been determined under strongly varying conditions, thus they should only be taken as a measure of the order of magnitude. The same holds for molecular weights, which were determined by different methods. [b] In ethylene homopolymerization. TO = turnovers $\equiv$ mol(substrate) per mol of metal. [c] For low molecular weight materials, narrow distributions of $M_{\mathrm{w}} / M_{\mathrm{n}}=2$ have also been reported. ${ }^{[15 \mathrm{e}]}$ [d] Polymerization in water as a reaction medium has been investigated only recently. ${ }^{[29 a, b]}$ 
unsuccessful. ${ }^{[16 a]}$ However, copolymerization of monomers containing a spacer between the vinyl moiety and the functional group, such as $\mathrm{H}_{2} \mathrm{C}=\mathrm{CH}-\left(\mathrm{CH}_{2}\right)_{8}-\mathrm{C}(\mathrm{O}) \mathrm{OMe}$, has been reported. ${ }^{[16]}$ Recently, copolymerization of ethylene with polar functionalized norbornenes by these types of nickel(II) catalysts has also been claimed. ${ }^{[19]}$ In the context of the preparation of branched polyethylenes with late transition metal catalysts, it can be noted that oligomerization of ethylene by P,O-chelated nickel(II) catalysts and subsequent copolymerization of the linear oligomers with ethylene using a typical chromium-based catalyst has been described as a route to long chain branched polyethylenes. ${ }^{[15 c, 20]}$

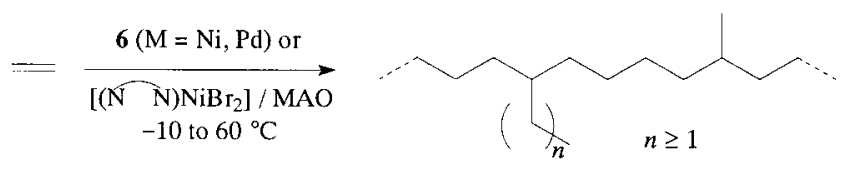

linear to highly branched ethylene homopolymer

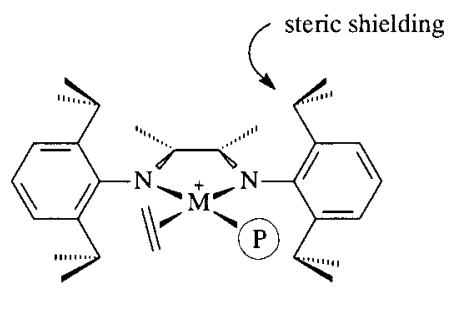

Scheme 5. Polymerization of ethylene by cationic $\mathrm{Ni}^{\mathrm{II}}$ and $\mathrm{Pd}^{\mathrm{II}}$ complexes with diimine ligands. $\mathrm{MAO}=$ methylalumoxane.

\section{Recent Findings-Cationic Catalysts with Multidentate Ligands}

In 1995, a report by Brookhart and co-workers on the discovery of a new class of catalysts for the polymerization of ethylene and $\alpha$-olefins was received with strong interest in academia and industry alike. ${ }^{[21]}$ These catalysts, based on known nickel(II) and palladium(II) complexes of bulky substituted diimine ligands, ${ }^{[22]}$ are unique in polymerizing ethyl-

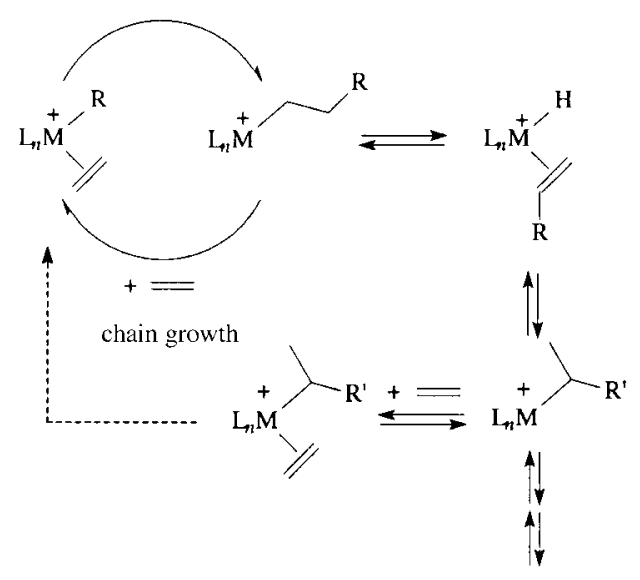

ene to highly branched, high molecular weight homopolymers at remarkable reaction rates (Scheme 5). Activities of up to $4 \times 10^{6} \mathrm{TOh}^{-1}$ were reported for the cationic $\mathrm{Ni}^{\mathrm{II}}$ catalysts, which thus approach rates typical of metallocenes. ${ }^{[23]}$ Polymer molecular weight distributions are relatively narrow and lie in the range expected for single-site catalysts. A key feature enabling polymerization to occur to very high molecular weights (Table 1 ) is retardation of chain transfer by the steric bulk of the $o$-aryl substituents $(\mathrm{R}=i \mathrm{Pr}$ or $\mathrm{Me})$. The $\mathrm{R}$ groups are located in an axial position above and below the squareplanar coordination plane as a consequence of a perpendicular arrangement of the aryl rings with respect to the latter. Initially, retardation of chain transfer was ascribed to a slowing of the associative displacement of the unsaturated polymer chain from the metal center by ethylene (Scheme 6a). Recent calculations on the $\mathrm{Ni}^{\mathrm{II}}$ catalyts alter-

formation of a methyl branch

formation of higher branches

a) Chain transfer by associative exchange:

"chain running"

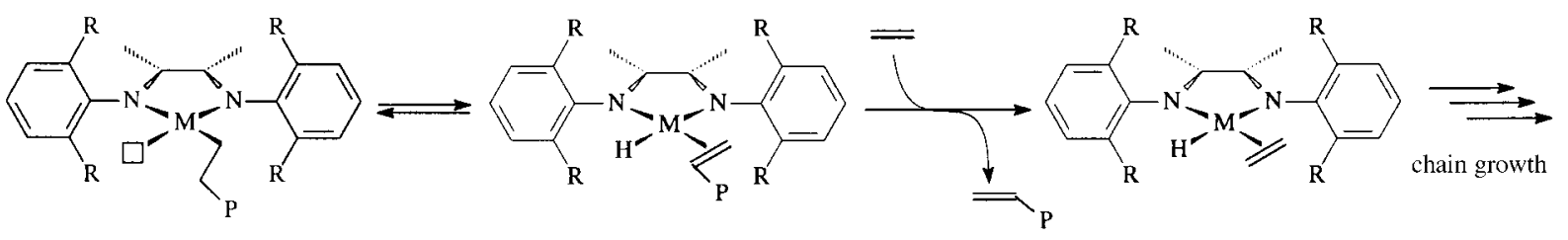

b) Chain transfer to monomer:

associative displacement

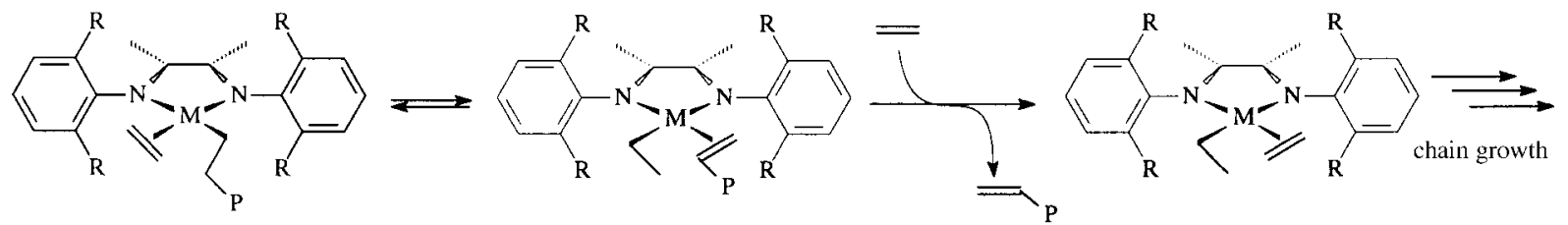

Scheme 6. Mechanism of branch formation in ethylene polymerization by cationic diimine-substituted $\mathrm{Pd}^{\mathrm{II}}$ and $\mathrm{Ni}^{\mathrm{II}}$ catalysts. Typical branching distribution $^{[21 \mathrm{~h}]}$ (per $1000 \mathrm{CH}_{2}$ ) obtained with a a) $\mathrm{Pd}^{\mathrm{II}}$ catalyst: Me 36, Et 26, Pr 3, Bu 12, amyl 2, hexyl and higher and end of chains 34; b) a Ni ${ }^{\mathrm{II}}$ catalyst: Me 41, Et 6, Pr 3, Bu 2, amyl 1, hexyl and higher and end of chains 5. 
natively suggest a direct $\beta$-H transfer to the monomer (Scheme 6b), the barrier of which increases with increasing bulk of the $o$-substituents. ${ }^{[21 \mathrm{~g}]}$ Introduction of the less bulky $\mathrm{R}=\mathrm{H}$ in the $\mathrm{Ni}^{\mathrm{II}}$ catalyts yields a highly active cationic catalyst for oligomerization of ethylene to linear $\alpha$-olefins. ${ }^{\text {[21d] }}$

The polyethylenes possess even- and also odd-number carbon branches (Me, Et, Pr, Bu, amyl, and longer branches). Whereas the polymers obtained with $\mathrm{Ni}^{\mathrm{II}}$ catalyts are dominated by methyl branches, the $\mathrm{Pd}^{\mathrm{II}}$ catalysts yield a large portion of longer branches and even a branch on a branch moiety, that is, an element of a hyperbranched structure. ${ }^{[21 \mathrm{~h}, \mathrm{j}]}$ These microstructures arise from a "chain-running" process (Scheme 6), similar to the aforementioned 2, $\omega$ polymerization reported by Fink et al. ${ }^{[21 a]}$ The $\mathrm{Pd}^{\mathrm{II}}$ catalysts yield highly branched amorphous polymers (approximately 100 branches per 1000 carbon atoms) irrespective of the ethylene concentration, ${ }^{[24]}$ whereas branching can be controlled with the $\mathrm{Ni}^{\mathrm{II}}$ catalysts by varying the ethylene concentration and polymerization temperature ( 1 to 100 branches per 1000 carbon atoms). Accordingly, the macroscopic properties of these polyethylenes-obtained from ethylene as the sole monomer-range from highly viscous (high molecular weight) liquids with a $T_{\mathrm{g}}$ of $-70^{\circ} \mathrm{C}$, over rubbery elastomeric materials, to rigid linear polyethylenes.

Remarkably, the $\mathrm{Pd}^{\mathrm{II}}$ catalysts also allow for the coordination copolymerization of ethylene and simple polar functionalized olefins, such as acrylates. ${ }^{[21 b, e]}$ With increasing acrylate incorporation into the copolymer, catalyst activity is lowered as a consequence of a reversible blocking of coordination sites by chelating binding of the carbonyl groups of incorporated acrylate (Scheme 7, equilibrium B). Chain running also results

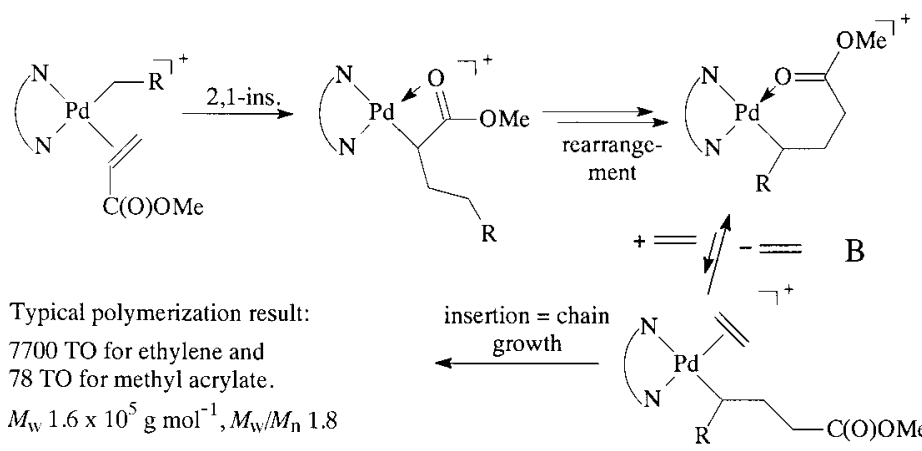

Scheme 7. Copolymerization of ethylene with acrylates yielding branched copolymers.

in predominant incorporation of acrylate at the ends of branches in the highly branched, amorphous copolymers. To date, there is no catalyst system capable of incorporating conventional polar monomers such as acrylates into the backbone of a linear polyethylene.

Brookhart and co-workers findings have resulted in a strongly increased interest in late transition metal olefin polymerization catalysis, and spurred an intense search for other suitable ligand structures. Subsequently, three different research groups (Brookhart, Gibson, and Bennett of DuPont) independently reported cationic iron and cobalt catalyst systems of structural type $\mathbf{7}$ for the polymerization of ethylene

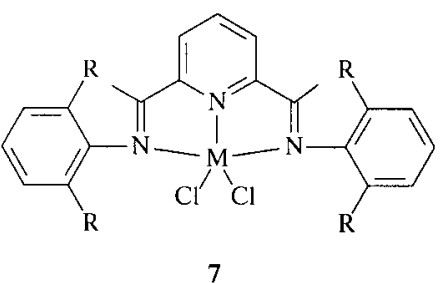

$\mathrm{M}=\mathrm{Fe}, \mathrm{Co}$

$\mathrm{R}=i \mathrm{Pr}, \mathrm{Me}$

activation e.g. by MAO

to highly linear, crystalline high-density polyethylene (HDPE). ${ }^{[25 a-d]}$ Astounding rates of up to $10^{7} \mathrm{TO} \mathrm{h}^{-1}$ (at 40 bar ethylene pressure) have been reported for the iron catalysts. The typical relative ease of preparation for many of the late transition metal catalyst systems highlighted is exemplified by the preparation of the iron catalysts from commercially available compounds as shown in Equation (3).
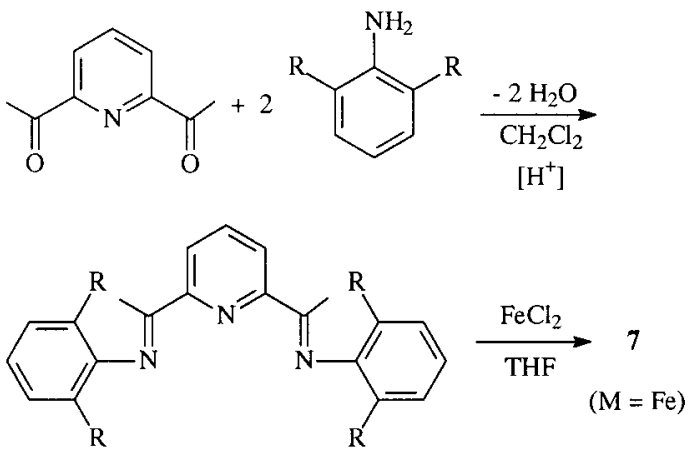

Broad or bimodal molecular weight distributions are obtained with the Fe catalysts as a result of chain transfer to aluminum as well as $\beta$-H elimination (Table 1 ). By contrast to the other catalyst systems discussed, up to now no single component catalyst precursors suitable as an alternative to the in situ aluminumalkyl-activated systems have been reported. BPAmoco and DuPont have announced a joint agreement aimed at a commercialization of the rigid polyethylenes prepared with iron catalysts. ${ }^{[25 \mathrm{~g}]} \mathrm{In}$ analogy to the previously mentioned diimine-substituted $\mathrm{Ni}^{\mathrm{II}}$ and $\mathrm{Pd}^{\mathrm{II}}$ catalysts, the steric bulk of the $o$-aryl substituents retards chain transfer. Reducing the steric bulk of the $o$-aryl substituents $\mathrm{R}$ in the iron complexes again yields catalysts for ethylene oligomerization. ${ }^{[25 e, f]}$ Astonishing activities of up to $10^{8} \mathrm{TOh}^{-1}$ for formation of $>99 \%$ linear $\alpha$-olefins were observed, far exceeding the activities reported for SHOP catalysts. From a viewpoint of historical development, it is interesting to note that the search for new polymerization catalysts and the resulting understanding has in turn yielded highly active new oligomerization systems.

\section{New Neutral Nickel(II) Catalysts with $\overparen{N O}$ Chelating Ligands}

Approximately simultaneously with the cationic iron and cobalt catalysts, a new class of neutral nickel catalysts based on salicylaldimine ligands ${ }^{[26]}(\mathbf{8})$ was reported independently by Johnson et al. ${ }^{[27]}$ and Grubbs and co-workers. ${ }^{[28]}$ These neutral nickel(II) complexes contain a formally monoanionic bidentate ligand and are thus related to SHOP-type catalysts. 
<smiles>[X]c1cc([Z])c2c(c1)C([R])N(c1c([R])cccc1[R])[N+](P)(c1ccccc1)O2</smiles>

$8 \mathbf{a}$

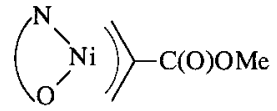

$8 \mathrm{~b}$
However, the $\mathrm{P}$ donor of the latter is replaced by a bulky substituted imine moiety. Moderately branched to linear polyethylenes are obtained with such catalyst systems. Similar weight-average molecular weights but considerably narrower molecular weight distributions are obtained than in materials prepared with traditional $\mathrm{P}, \mathrm{O}$-based catalysts (Table 1). Initially, substituted allyl complexes ${ }^{[27]}(\mathbf{8 b})$ or triphenylphosphane complexes ${ }^{[28]}(\mathbf{8 a})$ were used, which require a Lewis acid or phosphane scavenger, respectively, as a cocatalyst for effective polymerization. Introduction of bulky substituents R' in the ortho position of the phenolate moiety enables the use of phosphane complexes as single-component precursors without a phosphane scavenger as a result of facilitated dissociation of the triphenylphosphane ligand. ${ }^{[28 b]}$ Methyl complexes with weakly coordinating acetonitrile ligands, prepared according to Equation (4), represent very versatile

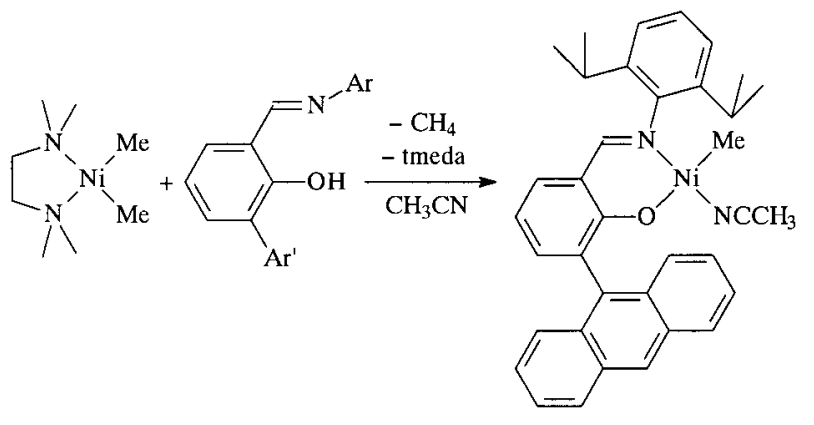

single-component catalyst precursors (tmeda $=N, N, N^{\prime}, N^{\prime}$-tetramethylethylenediamine). ${ }^{[27,28 \mathrm{~b}, \mathrm{c}]}$ Activities in ethylene homopolymerization $\left(2.3 \times 10^{5} \mathrm{TOh}^{-1} \text { at } 17 \mathrm{bar}\right)^{[28 \mathrm{~b}]}$ equal those achieved with optimized $\mathrm{P}, \mathrm{O}-$ based polymerization catalysts. Like P,O-based neutral nickel(II) catalysts, the N,O-substituted nickel systems are functional-group tolerant. Grubbs and co-workers have copolymerized ethylene with 5-functionalized norbornenes [Eq. (5)], ${ }^{[28 b, c]}$ and high molecular weight polymer was obtained in ethylene homopolymerization in the presence of added polar reagents, such as ethers, ethyl acetate, acetone, and also water. ${ }^{[28 b]}$ Such polymerizations in the

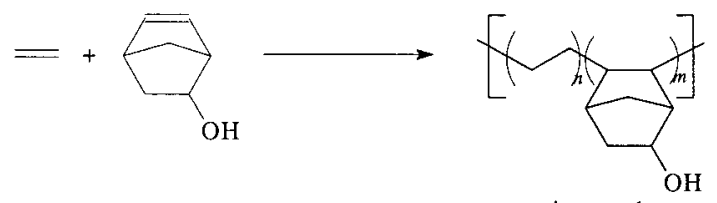

typical result: $M_{\mathrm{W}} 1.7 \times 10^{4} \mathrm{~g} \mathrm{~mol}^{-1}$ $460 \mathrm{TO}$ for ethylene, $34 \mathrm{TO}$ functionalized norbornene presence of added polar reagents are of interest with regard to polymerization of less rigorously purified monomers. ${ }^{[28 \mathrm{~b}]}$

On a different level, utilization of water as a reaction medium for olefin polymerization offers intriguing opportunities. The unique properties of water are illustrated by free radical emulsion and suspension polymerization with which stable polymer latices can be produced directly. Recent reports reveal that such reactions can be carried out by means of vinyl-type coordination polymerization using late transition metal catalysts. ${ }^{[29,6]}$

In summary, major advances have recently been achieved in the field of late transition metal catalyzed olefin polymerization. Novel polyolefin microstructures have become accessible, and copolymerization of simple polar comonomers has been achieved. Also, mechanistic investigations have strongly enhanced an understanding of the underlying principles. This insight has already resulted in a successful rational design of new catalysts. Recently reported neutral $\mathrm{Ni}^{\mathrm{II}}$ catalysts based on salicylaldimine ligands provide an example. The data currently available does not allow for a concise general picture of the new materials accessible in regard to polymer properties relevant for applications. However, the strong interest in these polymers can be expected to enhance a more comprehensive illumination of this topic in the near future.

[1] a) Ziegler Catalysts (Eds.: G. Fink, R. Mülhaupt, H. H. Brintzinger), Springer, Berlin 1995; b) H. H. Brintzinger, D. Fischer, R. Mülhaupt, B. Rieger, R. Waymouth, Angew. Chem. 1995, 107, 1255-1283; Angew. Chem. Int. Ed. Engl. 1995, 34, 1143-1170; c) W. Kaminsky, M. Arndt, Adv. Polym. Sci. 1997, 127, 143-187; d) M. Balsam, C. Lach, R.-D. Maier, Nachr. Chem. 2000, 48, 338-347; e) K. S. Whiteley in Ullmann's Encyclopedia of Industrial Chemistry, Vol. A21, 5th ed. (Eds.: W. Gerhartz, B. Elvers), VCH, Weinheim, 1992, pp. 488-517.

[2] Recent comprehensive reviews on late transition metal olefin polymerization catalysis: a) G. J. P. Britovsek, V. C. Gibson, D. F. Wass, Angew. Chem. 1999, 111, 448-468; Angew. Chem. Int. Ed. 1999, $38,428-447$; b) S. D. Ittel, L. K. Johnson, M. Brookhart, Chem. Rev. 2000, 100, 1169-1204; c) S. Mecking, Coord. Chem. Rev. 2000, 203, 325 -351; d) A. S. Abu-Surrah, B. Rieger, Angew. Chem. 1996, 108, 2427-2429; Angew. Chem. Int. Ed. Engl. 1996, 35, 2475-2477.

[3] Polymerization of dienes, cyclic olefins, alkynes, and $\alpha$-olefins, copolymerizations of olefins with carbon monoxide, as well as ring opening metathesis polymerization are not the focus of this overview.

[4] a) M. Peuckert, W. Keim, Organometallics 1983, 2, 594-597; b) W. Keim, F. H. Kowaldt, Erdöl Erdgas Kohle 1978, 78-79, 453-462; c) W. Keim, F. H. Kowaldt, R. Goddard, C. Krueger, Angew. Chem. 1978, 90, 493; Angew. Chem. Int. Ed. Engl. 1978, 17, 466-467; d) D. Vogt in Aqueous-Phase Organometallic Chemistry (Eds.: B. Cornils, W. A. Herrmann), Wiley-VCH, Weinheim, 1998, pp. 541-547.

[5] a) K. Ziegler, E. Holzkamp, H. Breil, H. Martin, Angew. Chem. 1955 , 67, $541-547$; b) K. Fischer, K. Jonas, P. Misbach, R. Stabba, G. Wilke, Angew. Chem. 1973, 85, 1002-1012; Angew. Chem. Int. Ed. 1973, 12, 943-953; c) G. Wilke, Angew. Chem. 1988, 100, 189-211; Angew. Chem. Int. Ed. Engl. 1988, 27, 185-206.

[6] For a very slow (1 TO per day) ethylene polymerization by a rhodium complex in water, see L. Wang, R. S. Lu, R. Bau, T. C. Flood, J. Am. Chem. Soc. 1993, 115, 6999-7000.

[7] Some ethylene polymerization catalysts with bulky monodentate ligands have also been reported, for an early example see [5c].

[8] Reviews: a) E. Drent, P. H. M. Budzelaar, Chem. Rev. 1996, 96, 663 681; b) A. Sen, Acc. Chem. Res. 1993, 26, 303-310; c) A. S. AbuSurrah, B. Rieger, Top. Catal. 1999, 7, 165-177.

[9] a) E. Drent, J. A. M. van Broekhoven, M. J. Doyle, J. Organomet. Chem. 1991, 417, 235-251; b) A. Sen, T. W. Lai, J. Am. Chem. Soc. 1982, 104, 3520-3522; c) F. C. Rix, M. Brookhart, P. S. White, J. Am. Chem. Soc. 1996, 118, 4746-4764. 
[10] a) N. Alperowicz, Chem. Week 1995, July 2, 22; b) Anonymous, Chem. Eng. News 2000, 78(9), 16.

[11] a) S. Breunig, W. Risse, Makromol. Chem. 1992, 193, 2915-2927; b) B. L. Goodall, D. A. Barnes, G. H. Benedikt, L. H. McIntosch, Proceedings of the 6th International Business Forum on Specialty Polyolefins (SPO'96), Schotland Business Research, 1996, pp. 121 142 ; c) A. L. Safir, B. M. Novak, Macromolecules 1995, 28, $5396-$ 5398; d) B. S. Heinz, W. Heitz, S. A. Krügel, F. Raubacher, J. H. Wendorff, Acta Polym. 1997, 48, 385-391.

[12] a) R. Bauer, H. Chung, G. Cannell, W. Keim, H. van Zwet (Shell), USA 3637636, 1972 [Chem. Abstr. 1971, 75, 130322r]; b) R. Bauer, H. Chung, K. W. Barnett, P. W. Glockner, W. Keim (Shell), US-A 3686159, 1972 [Chem. Abstr. 1972, 76, 15196m].

[13] a) W. Keim, R. Appel, A. Storeck, C. Krueger, R. Goddard, Angew. Chem. 1981, 93, 91-92; Angew. Chem. Int. Ed. Engl. 1981, 20, 116117; b) W. Keim, Ann. N.Y. Acad. Sci. 1983, 415, 191-200; c) A. Storeck, Dissertation, RWTH Aachen, 1980.

[14] a) V. M. Moehring, G. Fink, Angew. Chem. 1985, 97, 982-984; Angew. Chem. Int. Ed. Engl. 1985, 24, 1001-1003; b) R. Schubbe, K. Angermund, G. Fink, R. Goddard, Macromol. Chem. Phys. 1995, 196, $467-478$.

[15] a) K. A. Ostoja-Starzewski, J. Witte, Angew. Chem. 1985, 97, 610-612; Angew. Chem. Int. Ed. Engl. 1985, 24, 599-601; b) K. A. OstojaStarzewski, J. Witte, Angew. Chem. 1987, 99, 76-77; Angew. Chem. Int. Ed. Engl. 1987, 26, 63-64; c) K. A. Ostoja-Starzewski, J. Witte, K. H. Reichert, G. Vasiliou in Transition Metals and Organometallics as Catalysts for Olefin Polymerization (Eds.: W. Kaminsky, H. Sinn), Springer, Berlin, 1988, pp. 349-360; d) K. H. A. Ostoja-Starzewski, J. Witte, H. Bartl, DE-A 3336500, 1985 [Chem. Abstr. 1985, 103, 142517t]; e) K. A. Ostoja Starzewski, J. Witte in Transition Metal Catalyzed Polymerizations-Ziegler-Natta and Metathesis Polymerization (Ed.: R. P. Quirk), Cambridge University Press, Cambridge, 1988, pp. 472-496.

[16] a) U. Klabunde, S. D. Ittel, J. Mol. Catal. 1987, 41, 123-134; b) U. Klabunde, R. Mülhaupt, T. Herskovitz, A. H. Janowicz, J. Calabrese, S. D. Ittel, J. Polym. Sci. Part A 1987, 25, 1989-2003; c) U. Klabunde (DuPont), US-A 4698403, 1987 [Chem. Abstr. 1988, 108, 151134w].

[17] a) Occurence of five-coordinate polymerization active species in which the ylide ligand $\mathrm{L}$ coordinates to the nickel center is conceivable; b) reported polymer analyses reveal an essentially linear structure. ${ }^{[15,16]}$ In oligomers obtained with ylide-substituted catalysts at high catalyst concentrations, a vinylidene branching group has also been identified. ${ }^{[15 c]}$

[18] For example, K. Kurtev, A. Tomov, J. Mol. Catal. 1994, 88, 141-150.

[19] K. L. Makovetsky, E. S. Finkelshtein, V. I. Bykov, A. K. Bagdasaryan, B. L. Goodall, L. F. Rhodes (BFGoodrich), WO 98/56837, 1999 [Chem. Abstr. 1999, 130, 66910f].

[20] For the historical development of simultaneous ethylene oligomerization/copolymerization see footnote 175 in ref. [2b]; see also D. L. Beach, Y. V. Kissin, J. Polym. Sci. Polym. Chem. 1984, 22, 3027-3042 (short-chain branching).

[21] a) L. K. Johnson, C. M. Killian, M. Brookhart, J. Am. Chem. Soc. 1995, 117, 6414-6415; b) L. K. Johnson, S. Mecking, M. Brookhart, J. Am. Chem. Soc. 1996, 118, 267-268; c) C. M. Killian, D. J. Tempel, L. K. Johnson, M. Brookhart, J. Am. Chem. Soc. 1996, 118, $11664-$ 11665 ; d) C. M. Killian, L. K. Johnson, M. Brookhart, Organometallics 1997, 16, 2005-2007; e) S. Mecking, L. K. Johnson, L. Wang, M. Brookhart, J. Am. Chem. Soc. 1998, 120, 888-899; f) S. A. Svejda,
L. K. Johnson, M. Brookhart, J. Am. Chem. Soc. 1999, 121, $10634-$ 10635; g) D. P. Gates, S. A. Svejda, E. Onate, C. M. Killian, L. K. Johnson, P. S. White, M. Brookhart, Macromolecules 2000, 33, $2320-$ 2334, and references therein; h) L. K. Johnson, C. M. Killian, S. D. Arthur, J. Feldman, E. McCord, S. J. McLain, K. A. Kreutzer, M. A. Bennett, E. B. Coughlin, S. D. Ittel, A. Parthasarathy, D. Tempel, M. Brookhart (UNC-Chapel Hill/DuPont), WO 96/23010, 1996 [Chem. Abstr. 1996, 125, 222773t]; j) Z. Guan, P. M. Cotts, E. F. McCord, S. J. McLain, Science 1999, 283, 2059-2062.

[22] The chemistry of such diimine complexes has been investigated extensively: a) G. van Koten, K. Vrieze, Adv. Organomet. Chem. 1982, 21, 151-239; b) R. van Asselt, E. E. C. G. Gielens, R. Ruelke, K. Vrieze, C. J. Elsevier, J. Am. Chem. Soc. 1994, 116, 977-985; c) H. tom Dieck, M. Svoboda, T. Greiser, Z. Naturforsch. B 1981, 36, 823 832.

[23] For recent overviews of activities of metallocenes in ethylene polymerization see ref. [1c] and H. G. Alt, A. Köppl, Chem. Rev. 2000, 100, $1205-1222$.

[24] Also for the $\mathrm{Pd}^{\mathrm{II}}$ catalysts, ethylene concentration can influence the amount of longer branches formed, and hence affect polymer

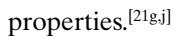

[25] a) B. L. Small, M. Brookhart, A. M. A. Bennett, J. Am. Chem. Soc. 1998, 120, 4049-4050; b) G. J. P. Britovsek, V. Gibson, B. S. Kimberley, P. J. Maddox, S. J. McTavish, G. A. Solan, A. J. P. White, D. J. Williams, Chem. Commun. 1998, 849-850; c) A. M. A. Bennett (DuPont), WO 98/27124, 1998 [Chem. Abstr. 1998, 129, 122973x]; d) G. J. P. Britovsek, M. I. Bruce, V. C. Gibson, B. S. Kimberley, P. J. Maddox, S. Mastroianni, S. J. McTavish, C. Redshaw, G. A. Solan, S. Strömberg, A. J. P. White, D. J. Williams, J. Am. Chem. Soc. 1999, 121, $8728-8740$; e) B. L. Small, M. Brookhart, J. Am. Chem. Soc. 1998, 120, $7143-7144$; f) G. J. P. Britovsek, S. Mastroianni, G. A. Solan, S. P. D. Baugh, C. Redshaw, V. C. Gibson, A. J. P. White, D. J. Williams, M. R. J. Elsegood, Chem. Eur. J. 2000, 6, 2221-2231; g) Anonymous, Chem. Eng. News 2000, 78(8), 9.

[26] Ethylene polymerization by other N,O-substituted (pyridine-carboxylato) nickel(II) complexes, which occurs with a comparatively low rate, has previously been reported: S. Y. Desjardins, K. J. Cavell, J. L. Hoare, B. W. Skelton, A. N. Sobolev, A. H. White, W. Keim, J. Organomet. Chem. 1997, 544, 163-174.

[27] L. K. Johnson, A. M. A. Bennett, S. D. Ittel, L. Wang, A. Parthasarathy, E. Hauptman, R. D. Simpson, J. Feldman, E. B. Coughlin (DuPont), WO 98/30609, 1998 [Chem. Abstr. 1998, 129, 149362j].

[28] a) C. Wang, S. Friedrich, T. R. Younkin, R. T. Li, R. H. Grubbs, D. A. Bansleben, M. W. Day, Organometallics 1998, 17,3149-3151; b) T. R. Younkin, E. F. Connor, J. I. Henderson, S. K. Friedrich, R. H. Grubbs, D. A. Bansleben, Science 2000, 287, 460-2; c) R. H. Grubbs, presentation at the 219th ACS National Meeting, San Francisco, March 27, 2000 (paper 230).

[29] Ethylene polymerization: a) A. Held, F. M. Bauers, S. Mecking, Chem. Commun. 2000, 301 -302; b) A. Tomov, J.-P. Broyer, R. Spitz, Macromol. Symp. 2000, 150, 53-58; ethylene-CO copolymerization: c) Z. Jiang, A. Sen, Macromolecules 1994, 27, 7215-7216; d) G. Verspui, G. Papadogianakis, R. A. Sheldon, Chem. Commun. 1998, $401-402$; e) C. Bianchini, H. Man Lee, A. Meli, S. Moneti, V. Patinec, G. Petrucci, F. Vizza, Macromolecules 1999, 32, 3859-66; f) G. Verspui, F. Schanssema, R. A. Sheldon, Angew. Chem. 2000, 112, 825-827; Angew. Chem. Int. Ed. 2000, 39, 804-806. 